\title{
Land Use/Land Cover Changes of Ago-Owu Forest Reserve, Osun State, Nigeria Using Remote Sensing Techniques
}

\author{
Meshach O. Aderele1, Tomiyosi S. Bola ${ }^{1,2^{*}}$, David 0. Oke ${ }^{1}$ \\ ${ }^{1}$ Federal University of Technology, Akure, Nigeria \\ ${ }^{2}$ University of British Columbia, Vancouver, Canada \\ Email: ^tomiyosishadrackbola@gmail.com
}

How to cite this paper: Aderele, M. O., Bola, T. S., \& Oke, D. O. (2020). Land Use/Land Cover Changes of Ago-Owu Forest Reserve, Osun State, Nigeria Using Remote Sensing Techniques. Open Journal of Forestry, 10, 401-411.

https://doi.org/10.4236/ojf.2020.104025

Received: August 25, 2020

Accepted: September 27, 2020

Published: September 30, 2020

Copyright $\odot 2020$ by author(s) and Scientific Research Publishing Inc. This work is licensed under the Creative Commons Attribution International License (CC BY 4.0).

http://creativecommons.org/licenses/by/4.0/

\section{(c) (i) Open Access}

\begin{abstract}
Remote sensing (RS) and GIS are important methods for land use assessment and land cover transition. In this study, land use/land cover changes in the Ago-Owu Forest Reserve, Osun State, Nigeria have been assessed. Landsat 5 TM, Landsat 7 ETM+ and Landsat 8 OLI were acquired for 1986, 2002 and 2017 respectively. The three scenes corresponded to path 190 and row 055 of WRS-2 (Worldwide Reference System). The processing of the imagery was preceded by the clipping of the study area from the satellite image. The boundary of the reserve was carefully digitized and used to clip the imagery to produce an image map of the forest reserve. Using the supervised image classification procedure, training sites were used to produce land use/land cover maps. The same classification scheme was used for the 1986, 2002 and 2017 images to facilitate the detection of change. The differences in the area covered by the different polygons between the three sets of images were measured in $\mathrm{km}^{2}$. The results show that during 1986 and 2017, there is a dramatic increase of build-up areas with a change of $55.65 \mathrm{~km}^{2}$ and sparse vegetation (farmland and grassland) with a change of $53.97 \mathrm{~km}^{2}$, while a dramatic decrease of dense vegetation (forest areas) with a change of $109.61 \mathrm{~km}^{2}$. The consequence of these results is that over the years, the population of people living in the forest reserve has increased and many of them are engaged in farming, leading to an increase in farmland. In addition, logging activities continued unabated in the forest reserve, as demonstrated by a sharp increase in the deforested area within the reserve. The maps produced in this study will serve as a planning tool for the Osun State Forestry Department to plan reforestation activities for the forest reserve.
\end{abstract}

\section{Keywords}

Remote Sensing, Landsat, Forest Reserve, Geographical Information System, 
Land Use and Land Cover Changes

\section{Introduction}

Changes in land use and land cover are increasing globally and causing significant environmental issues and therefore need to be mapped (Ringrose et al., 1997). Change in land cover is the single and most important variable of global change affecting ecological systems (Zhou, Li, \& Kurban, 2008) with an environmental impact that is at least associated with climate change (Skole, 1994). Change in land cover is a common phenomenon in all parts of the world. Such changes may be rapid (e.g. forest clearing for agriculture) or relatively slow (e.g. tree damage and death due to acid rain) (Skidmore, 2002) and may affect both socio-economic and ecological conditions (Aspinall, 2006). According to Phat et al. (2004), the 21st century brought new challenges to forest management and forest ecosystems. This is potentially an extremely important tool for dealing with climate change, in addition to improving human actions (Cai et al., 2011). Policymakers and scientists need to know the spatial dimensions of land use and land use consistently in order to be sufficiently prepared to make informed decisions on land resources.

A wide range of scientists and practitioners, including earth systems scientists, land and water managers as well as urban planners, are therefore seeking information on the location, distribution, type and magnitude of land use and land cover change (Weng, 2002). Nigeria has been under intense pressure in the tropical rainforests of the southwest, due to the rapid growth of the country's population and economy. In the 1920s, the forest reserves that had pioneered the establishment of reserves were not spared from the uncontrollable removal of forest products, which caused rapid changes in the pattern of land cover in these areas. Resources have shown that natural vegetation has been damaged and rapidly transformed as a result of over logging, conversion to forest plantations (Gmelina arborea) and large-scale farming. Excessive uncontrolled hunting for trade in bush meat (Oates et al., 2008) has also decimated their wildlife populations. Despite the immense advantages of forests, agencies and organizations have reported significant losses in forests due to unfavorable forestry practices worldwide (FAO, 1997). For effective land use planning, landscape monitoring, natural resource management and habitat assessment, land use/cover change mapping provides resourceful and valuable information for land resource management and for projecting future trends in land efficiency for productivity (Al-Bakri et al., 2013).

These changes have an impact on the ecological stability of forest regions and thus identify and investigate the status of a resource such as forest cover, which is a key part of the management and monitoring of resources from a local or global perspective (Marçal et al., 2005). Remote Sensing (RS) and Geographic Information Systems (GIS) have proved to be one of the most accurate means of 
measuring the extent and pattern of changes in land patterns over time (Quan et al., 2013; Gebiaw et al., 2018; Chen, 2002; Amna et al., 2015; Sekela \& Manfred, 2019; Duguma, 2017). Techniques also provide a viable source of data from which updated information on land cover can be extracted efficiently and cheaply in order to monitor changes in land cover (Fichera et al., 2012). The aim of the study is to apply GIS and remote sensing techniques to assess changes in land use/cover during the years 1986 to 2017 in the Ago Owu Forest Reserve Area in Osun State, Nigeria. The specific goals are: 1) to identify the changes that occurred within the period covered by the images, and 2) to determine the amount and rate of changes within the study period.

\section{Geographic Background}

Ago Owu Forest Reserve is a forest located in Isokan local government of Osun State in South-west Nigeria. The Forest Reserve is positioned between Latitude: 7.046 and 7.252 and between Longitude: 4.066 and 4.387. The forest reserve shares a common boundary with other forest reserves which are Ife forest reserve, Shasha forest reserve and Omo forest reserve as shown in the map in Figure 1. Although the vegetation of area is classified by Keay (1959) along with the rest of the Nigeria High Forest as Tropical Lowland Rain Forest. The forest type was recognized as Dry Forest type as distinct from Wet forest of the Southern part of Omo Forest Reserve.

\section{Research Methods}

The template is used to format your paper and style the text. All margins, column widths, line spaces, and text fonts are prescribed; please do not alter them.

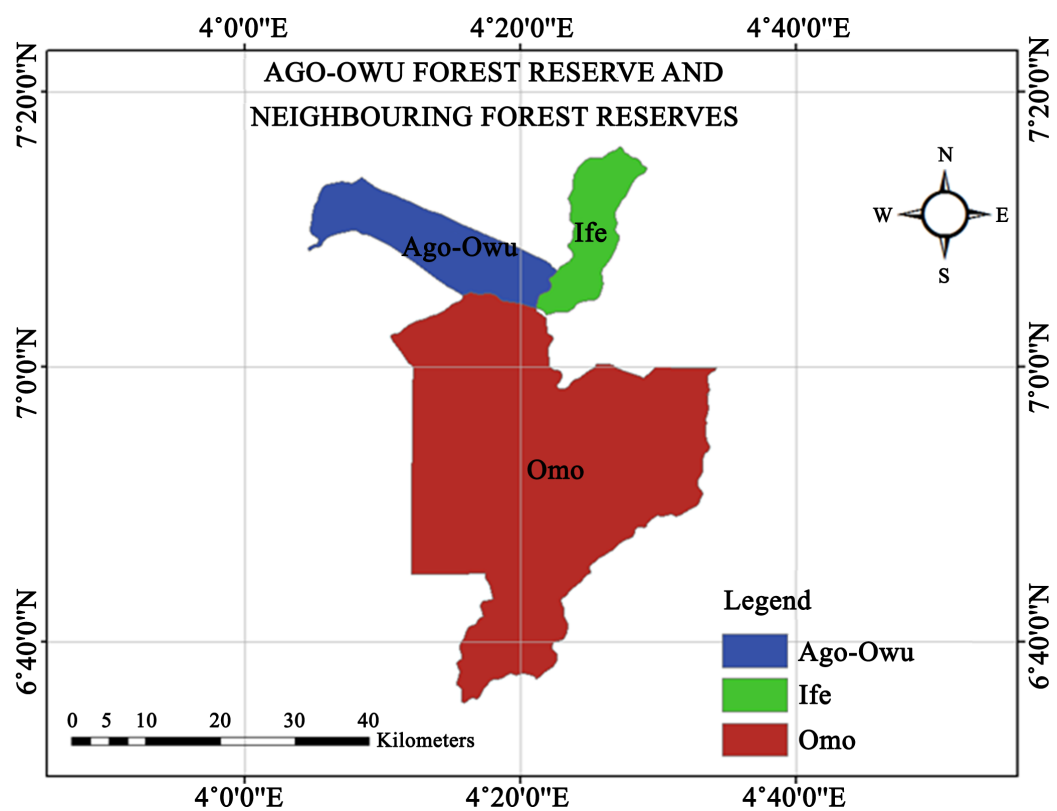

Figure 1. Ago Owu forest reserve and surrounding forest reserves. Source: Image adapted from ArcGIS 10.3.1. 
You may note peculiarities. For example, the head margin in this template measures proportionately more than is customary. This measurement and others are deliberate, using specifications that anticipate your paper as one part of the entire journals, and not as an independent document. Please do not revise any of the current designations.

\subsection{Data Description}

The image used in this study was acquired from the official website of Landsat (https://landsat.usgs.gov/). Landsat 5 TM for 1986, Landsat 7 ETM+ for 2002 and Landsat 8 OLI were acquired for 2017. The four scenes corresponded with path 190 and row 055 of the WRS-2 (Worldwide Reference System). The scenes were cloud-free and could have a partial radiometric quality which can be later adjusted by carrying out radiometric correction on it. The Landsat image of the study area was extracted through a process called masking i.e. the overlay of the forest reserve boundary map on each of the scenes and finally creating a new raster layer perfectly showing the area of study while other parts are being thinned out.

\subsection{Image Processing}

Image processing was done to provide a georeferenced image, compare/overlay multiple images, merge with map layers, and mosaic images. For this research, Geometric Correction was used to remove geometric distortions from a distorted image. This was achieved by establishing the relationship between the image coordinate system and the geographic coordinate system using calibration data of the sensor, measured data of position and altitude, ground control points, atmospheric condition etc.. Also, Radiometric Correction was used to remove the sensor or atmospheric noise, to more accurately represent ground conditions.

\subsection{Ground Truthing and Image Classification}

Landsat 8 OLI image acquired for 2016 was pre-classified thereby making all study sites available, the pre-classified image was taken to the study site to confirm if what was classified was the same as what was on the ground. This was done by using a global positioning system (GPS) to locate the coordinates of suggested features on the ground and thereafter loading the coordinates on ArcGIS Software for image classification. The supervised image classification was used by developing the spectral signatures of known categories such as urban and forest areas. The software was used to assign the pixel in each of the images to the cover type which signature has the highest similarity. Specifying the classes of interest for land cover is done by the software but with the guidance of the user. The user defines areas called "training sites" which are areas in the map that are known to represent a land cover type for each land cover type being assessed. The spectral signature of each pixel in each of the training areas 
is determined by the software and the information acquired is used to define the variance and mean of the classes as it relates to every input band (Megan, 2012). Each pixel in the image was assigned, based on its spectral signature, to the class it most closely matches. Training areas that cover the full range of variability within each land cover type was chosen to allow the software to accurately classify the rest of the image. Software used in this research are, ArcMap, ArcGIS, and Universal Map Downloader.

\section{Results and Discussion}

Table 1 shows the extent of land use types and changes in land use in the study area between 1986 and 2007. In 1986, dense vegetation covered an area of 199.99 $\mathrm{km}^{2}$ which reduced to $137.07 \mathrm{~km}^{2}$ in 2002 and to $90.38 \mathrm{~km}^{2}$ in 2017 . Sparse vegetation increased in extent from $13.995 \mathrm{~km}^{2}$ in 1986 to $67.96 \mathrm{~km}^{2}$ in 2017 . While the built-up area increased from $24.25 \mathrm{~km}^{2}$ to $80.09 \mathrm{~km}^{2}$.

The results of this study show how modern technologies such as remote sensing and geographical information systems (GIS) can serve as a tool measuring the extent and pattern of changes in landscape conditions over time which agrees with past work of (Quan et al., 2013; Gebiaw et al., 2018; Chen, 2002; Amna et al., 2015; Sekela \& Manfred, 2019; Duguma, 2017).

\subsection{Land Use/Land Cover Types}

The various types of land use in Ago Owu Forest Reserve were classified into five major groups namely: Dense Vegetation, Sparse Vegetation, Built-up, Roads and Water lines. The land use types for 1986, 2002 and 2017 are shown in Figures 2-4. The spatial distribution of land use types in the study area is illustrated in Table 1 . This was done by supervised classification.

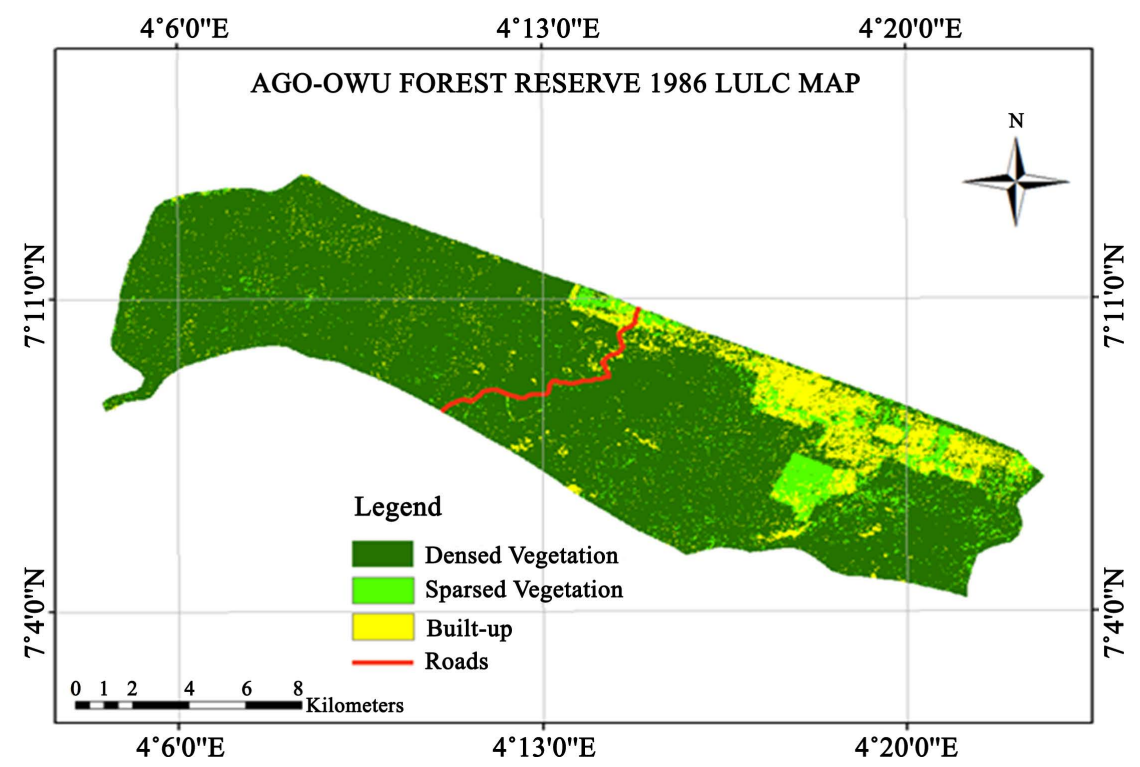

Figure 2. Land use type 1986 of the study area (source: image adapted from ArcGIS 10.3.1). 


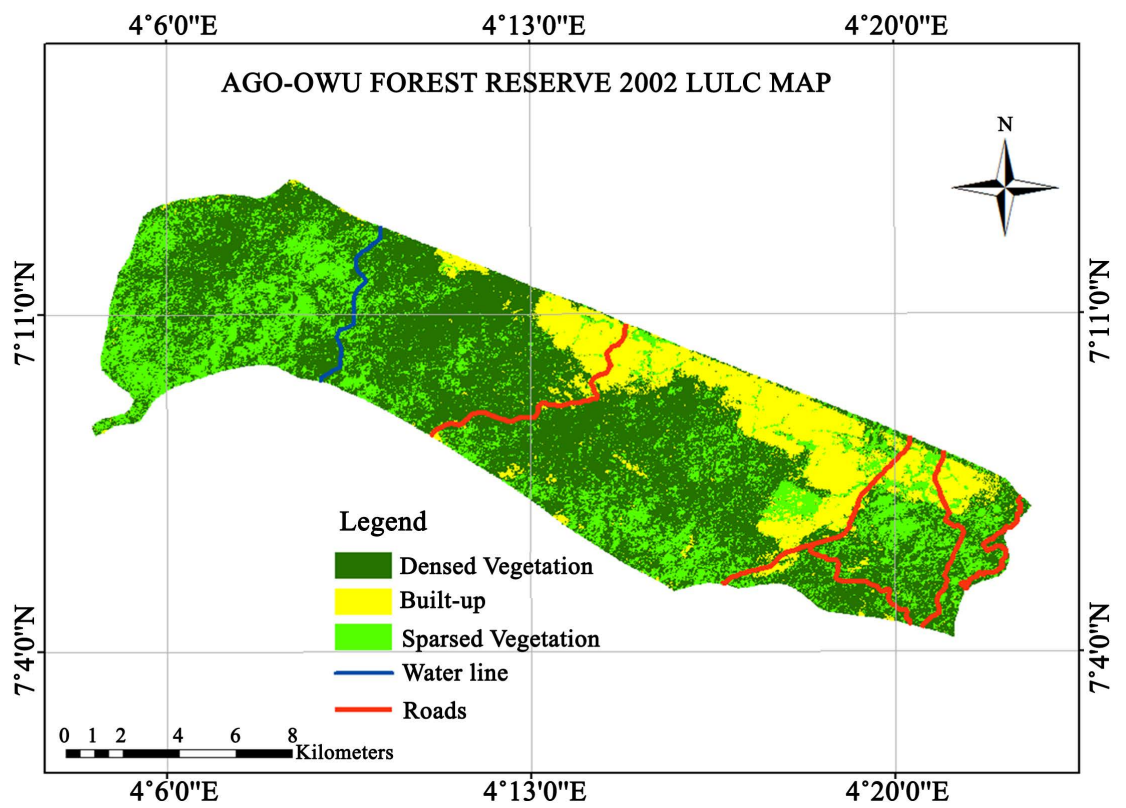

Figure 3. Land use type 2002 of the study area (source: image adapted from ArcGIS 10.3.1.

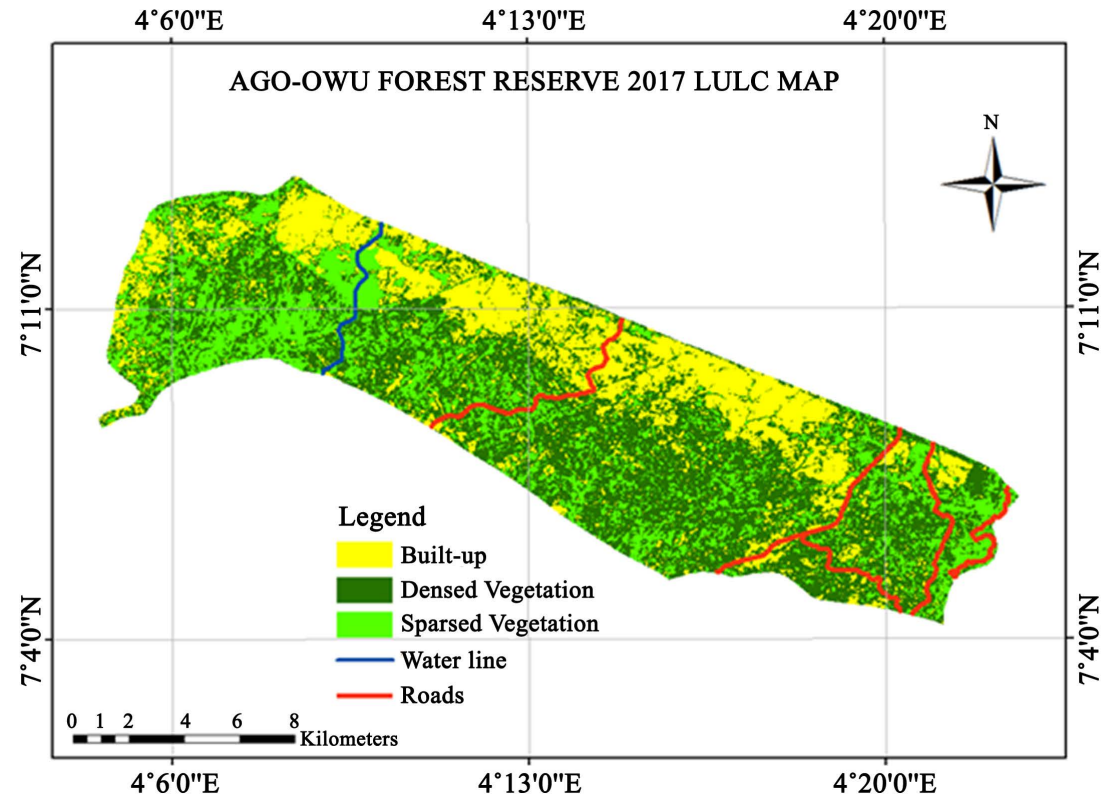

Figure 4. Land use type 2017 of the study area (source: image adapted from ArcGIS 10.3.1).

Table 1. Extent of land use types and changes in land use type in the study area between 1986 and 2017.

\begin{tabular}{ccccc}
\hline Land use Type & $\mathbf{1 9 8 6}\left(\mathrm{km}^{2}\right)$ & $\mathbf{2 0 0 2}\left(\mathrm{km}^{2}\right)$ & $\mathbf{2 0 1 7}\left(\mathrm{km}^{2}\right)$ & Change $\left(\mathrm{km}^{2}\right)$ \\
\hline Dense Vegetation & 199.99 & 137.07 & 90.38 & -109.61 \\
Sparse Vegetation & 13.99 & 63.98 & 67.96 & 53.97 \\
Built-up & 24.45 & 37.38 & 80.10 & 55.65 \\
Total & 238.43 & 238.43 & 238.43 &
\end{tabular}


The dense vegetation which consist of the natural forest, plantation forest where the natural forest consists of species such as Triplochiton sclerexylon, Terminalia superba, Celtis zenkerii, Funtumia elastica, Pycnanthus angolensis, Milicia excelsa etc.. And the plantation forest which consists of Tectona Grandis, Gmelina arborea. The sparse vegetation consists of the agricultural and grass land and the built-up consists of the settlements and where no vegetation exists. The loss of the dense vegetation (Natural and Plantation) forest to Agricultural lands is a clear indication of an intensive rate of deforestation in the study area. This result correlates with the view of Lieberman \& Amaya-Jackson (2005), that deforestation is largely due to clearance of Forest land for Agriculture and other human activities. According to World Bank (1991), the clearance of the forest each year is due to the quest of the rural dwellers for more agricultural lands. The common farming practice, which is fallow system, entails that farmers abandon a piece of land for some years to recover. While they allow the land to fallow, they seek new fertile land and the alternative place to go is the forest. Other reasons could be attributed to high rise in poverty level and population size. All these leave the people with no alternative than to seek more forest land to satisfy their need for more farmland.

\subsection{Land Use Change Map}

The final LULC map of 2017 in Figure 4 indicates visual changes in land use change that took place in Ago Owu Forest Reserve between 1986, 2002 and 2017 and also makes us know the present state of the forest reserve. This image highlights the changes in vegetation and qualitatively assesses the extent of the change. This technique showed clearly areas where changes have taken place in Ago Owu Forest Reserve. Where dense vegetation still exists is dark green, where sparse vegetation still exists is fir green and where built-up exist is yellow, the water line is displayed in blue and the roads are displayed in red.

\subsection{Statistical Analysis}

Changes in each land use type over the thirty years period 1986 to 2017 are summarized in Table 1 and graphically represented in Figures 5-7, and are also discussed in this section. There are significant increases in the spatial extent Built-up and sparse vegetation while dense vegetation decreased significantly in extent.

\subsubsection{Dense Vegetation}

The reserve has witnessed deforestation, degradation and encroachment, this is reflected in the reduction of the area occupied by Plantation and Natural Forest from $199.99 \mathrm{~km}^{2}$ to $90.38 \mathrm{~km}^{2}$, and this is largely due to increase in farming practices and population. The harvesting of forest products by the occupants resulted in significant loss of forest area and increase in Settlements and Farmland. Other factors contributing to the damage of natural forests include the encroachment of new settlements and infrastructure development in the reserve. 
LULC 1986

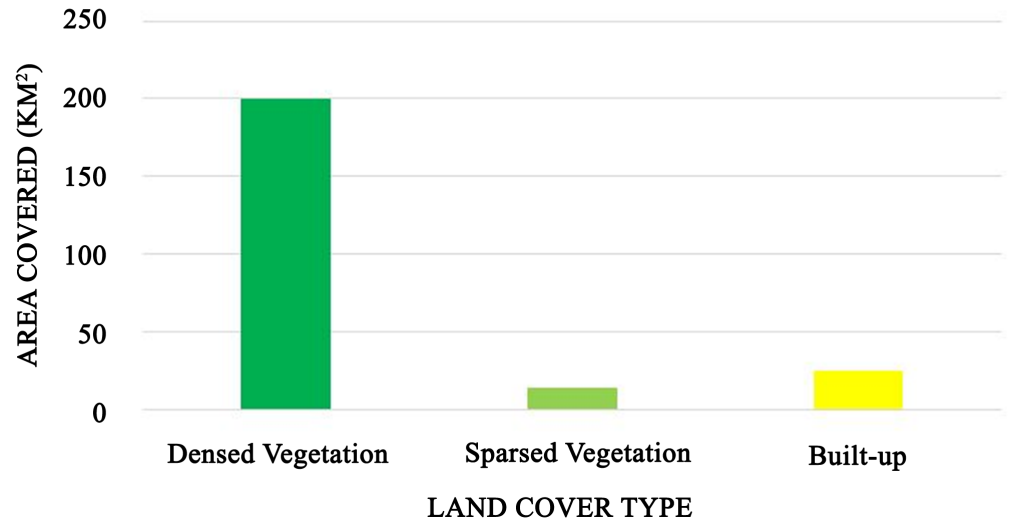

Figure 5. Graph of land use type 1986 and area covered in the study area.

LULC 2002

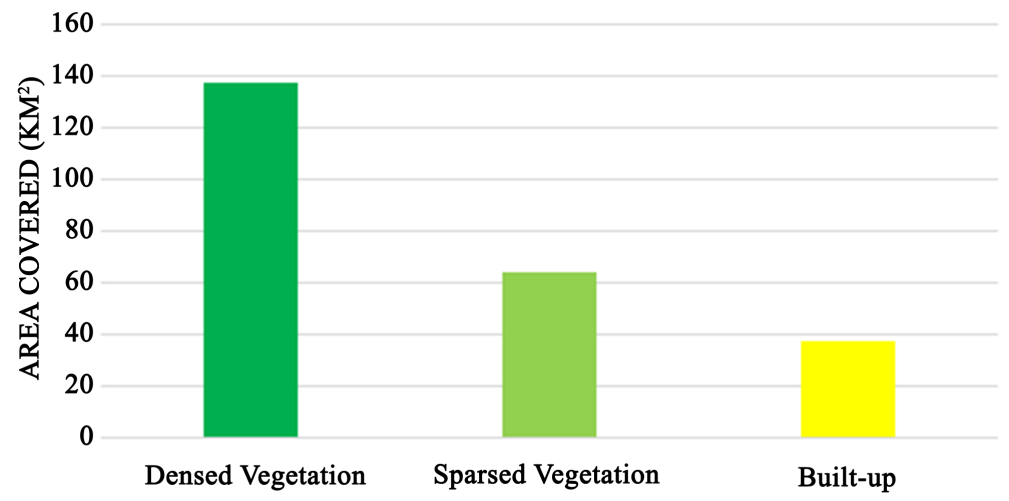

LAND COVER TYPE

Figure 6. Graph of land use type 2002 and area covered in the study area.

LULC 2017

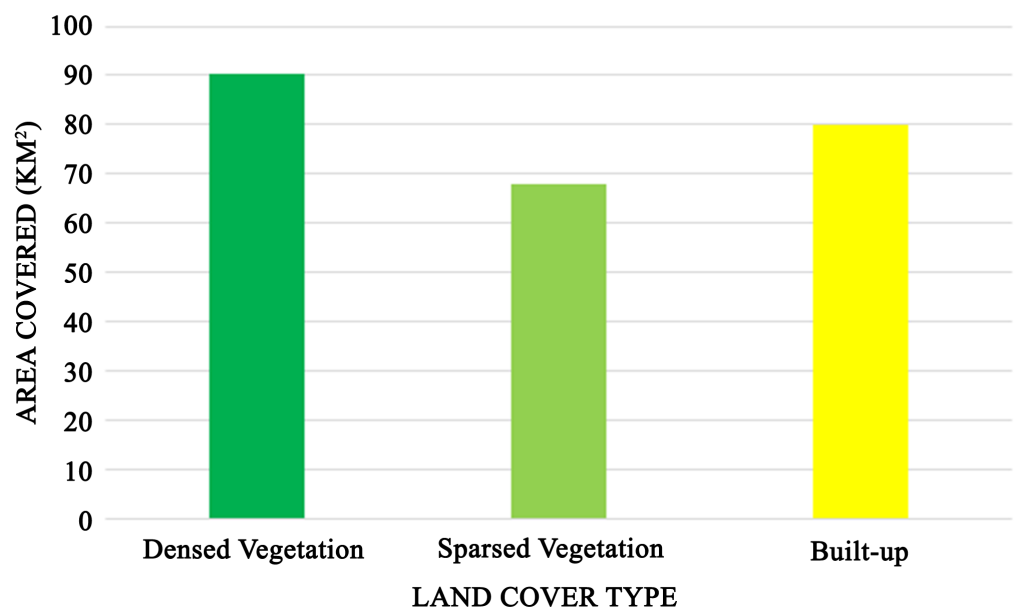

Figure 7. Graph of land use type 2017 and area covered in the study area. 
The predominant subsistence agricultural practices signify a gradual but chronic degradation of the forest. Some areas within the reserve have been eroded. The impacts of deforestation are very pronounced in the part of the Natural and plantation forest. This portrays high level of degradation, the area is covered with grass, barren land and farmland. The change is presently due to illegal and uncontrolled logging which has destroyed a lot of the forest rendering them exposed to farmers for agricultural purpose and expansion of settlements etc.

\subsubsection{Sparse Vegetation}

The total land within the Ago Owu Forest Reserve that was converted from various types to Agricultural land and grass land between 1986 and 2017 amounted to $53.97 \mathrm{~km}^{2}$. The increase in Agricultural land and grass land occurred mainly at the expense of Natural forest and Plantation forest. The expansion of Agricultural land and grass land indicates increased highly and consequently Plantation and Natural Forest experienced deforestation, degradation and exploitation due to cultivation and demand for wood resources. The rich soils are more exposed to agricultural expansion because most of the soils in the Reserve are rich in nutrients and ideal for agricultural production.

\subsubsection{Built-Up}

Spatial extents in settlement and non-vegetated areas show an overall obvious increase in settlements. Changes in this land use type depict higher changes from Plantation, Natural Forest. Most of the emerging towns portray an increase in settlement area signifying an increment in population. The high population growth has translated into rapidly increasing demands for land in terms of food, shelter, energy (in particular, fuelwood) and construction materials. Conclusively, settlement and non-vegetated area expansion is primarily due to population increase between the time period.

\section{Conclusion}

For the effective management of forest land, conservation and planning of forest resources, precise, frequent and timely data are required. These data could be obtained through RS and GIS technologies. Therefore, this study revealed the use of GIS and remote sensing, modern technologies in assessing the extent and pattern of changes in forest landscape over time which agrees with (Mukete et al., 2017). In addition, the ability of GIS and Remote Sensing in capturing spatial-temporal data was also shown. Three major land use and land cover changes over time were determined in Ago Owu Forest Reserve. There was a reduced rapid change in the dense vegetation cover of the study area between the periods of 1986 and 2017. This information could be very useful in the sustainable forest management, biodiversity and environmental conservation and the protection of the forest resources.

\section{Acknowledgements}

The authors sincerely appreciate Prof. D.O Oke of Forestry and Wood Technol- 
ogy, Federal University of Technology Akure, Prof. S.O Akindele of Forestry and Wood Technology, Federal University of Technology Akure and Mr. Olumide Akande of Center for Space research and Application, Federal University of Technology, Akure for their unquantifiable support in the course of this research work.

\section{Conflicts of Interest}

The authors declare no conflicts of interest regarding the publication of this paper.

\section{References}

Al-Bakri, J. T., Salahat, M., Suleiman, A., Suifan, M., Hamdan, M. R., Khresat, S., \& Kandakji, T. (2013). Impact of Climate and Land Use Changes on Water and Food Security in Jordan: Implications for Transcending "The Tragedy of the Commons". Sustainability, 5, 724-748. https://doi.org/10.3390/su5020724

Amna, B., Rabia, S., Sheikh, S. A., \& Neelam, A. (2015). Land Use Change Mapping and Analysis Using Remote Sensing and GIS: A Case Study of Simly Watershed, Islamabad, Pakistan. The Egyptian Journal of Remote Sensing and Space Sciences, 18, 251-259. https://doi.org/10.1016/j.ejrs.2015.07.003

Aspinall, R. (2006). Editorial. Journal of Land Use Science, 1, 1-4. https://doi.org/10.1080/17474230600743987

Cai, W. W., Song, J. L., Wang, J. D., \& Xiao, Z. Q. (2011). High Spatial- and Temporal-Resolution NDVI Produced by the Assimilation of MODIS and HJ-1 Data. Canadian Journal of Remote Sensing, 37, 612-627. https://doi.org/10.5589/m12-004

Chen, X. (2002). Using Remote Sensing and GIS to Analyse Land Cover Change and Its Impacts on Regional Sustainable Development. International Journal of Remote Sensing, 23, 107-124. https://doi.org/10.1080/01431160010007051

Duguma, E. (2017). Remote Sensing-Based Urban Land Use/Land Cover Change Detection and Monitoring. Journal of Remote Sensing \& GIS, 6, 2.

FAO (1997). State of the World's Forests, 1997. Rome: Food and Agriculture Organization of the United Nations. http://www.fao.org/forestry

Fichera, C. R., Modica, G., \& Pollino, M. (2012). Land Cover Classification and Change-Detection Analysis Using Multi-Temporal Remote Sensed Imagery and Landscape Metrics. European Journal of Remote Sensing, 45, 1-18. https://doi.org/10.5721/EuJRS20124501

Gebiaw, T. A., Aschalew, K. T., Solomon, S. D., Mulugeta, A. B., Mengistu, A. J., Wondie, M. T., Dereje, T. M., \& Engidasew, Z. T. (2018). Time Series Land Cover Mapping and Change Detection Analysis Using Geographic Information System and Remote Sensing, Northern Ethiopia. Journal of Air, Soil and Water Research, 11.

Keay, R. W. (1959). An Outline of the Nigerian Vegetation. Lagos: Federal Department of Forest Research, Federal Ministry of Information.

Lieberman, A. F., \& Amaya-Jackson, L. (2005). Reciprocal Influences of Attachment and Trauma: Using a Dual Lens in the Assessment and Treatment in Infants, Toddlers, and Preschoolers. In L. Berlin, Y. Ziv, L. Amaya-Jackson, \& M. T. Greenberg (Eds.), Enhancing Early Attachments: Theory, Research, Intervention, and Policy (pp. 120-126). New York: Guilford Press.

Marçal, A. R. S., Borges, J. S., Gomes, J. A., \& Da Costa, J. F. P. (2005). Land Cover Up- 
date by Supervised Classification of Segmented ASTER Images. International Journal of Remote Sensing, 26, 1347-1362. https://doi.org/10.1080/01431160412331291233

Megan, K. C. (2012). Supervised Classification. The Landscape Toolbox: Tools \& Methods for Effective Land Health Monitoring.

https://wiki.landscapetoolbox.org/doku.php/remote_sensing_methods:supervised_clas sification

Mukete, B., Sun, Y., Baninla, Y., Achem, B. J., Bakia, M., Sajjad, S., Tamungang, R., Jaba, W., \& Chalwe, P. (2017). Perspectives of Remote Sensing and GIS Applications in Tropical Forest Management. American Journal of Agriculture and Forestry, 5, 33-39. https://doi.org/10.11648/j.ajaf.20170503.11

Oates, J. F., Ikemeh, R. A., Ogunsetan, A., \& Bergl, R. A. (2008). A Survey of Rain Forests in Ogun, Ondo and Osun States in Southwestern Nigeria to Assess Options for Their Sustainable Conservation. Lagos: Nigerian Conservation Foundation.

Phat, N. K., Knorr, W., \& Kim, S. (2004). Appropriate Measures for Conservation of Terrestrial Carbon Stocks-Analysis of Trends of Forest Management in Southeast Asia. Forest Ecology and Management, 191, 283-299. https://doi.org/10.1016/j.foreco.2003.12.019

Quan, B., Xiao, Z., Römkens, M., Bai, Y., \& Lei, S. (2013). Spatiotemporal Urban Land Use Changes in the Changzhutan Region of Hunan Province in China. Journal of Geographic Information System, 5, 136-147. https://doi.org/10.4236/jgis.2013.52014

Ringrose, S., Vanderpost, C., \& Maheson, W. (1997). Use of Image Processing and GIS Technique to Determine the Extent and Possible Causes of Land Management/Fenceline Induced Degradation Problems in the Okavango Area, Northern Botswana. International Journal of Remote Sensing, 18, 2337-2364. https://doi.org/10.1080/014311697217648

Sekela, T., \& Manfred, F. B. (2019). Land-Use and Land-Cover (LULC) Change Detection in Wami River Basin, Tanzania. Land, 8, 136.

Skidmore, A. K. (2002). Land Use and Land Cover. New York: Marcel Dekker, Inc.

Skole, D. L. (1994). Data on Global Land Cover Change: Acquisition, Assessment and Analysis. In W. B. Turner II (Ed.), Changes in Land Use and Land Cover: A Global Perspective (pp. 437-471). Cambridge: Cambridge University Press.

Weng, Q. (2002). Land Use Change Analysis in the Zhujiang Delta of China Using Satellite Remote Sensing, GIS and Stochastic Modelling. Journal of Environmental Management, 64, 273-284. https://doi.org/10.1006/jema.2001.0509

Zhou, Q., Li, B., \& Kurban, A. (2008). Trajectory Analysis of Land Cover Change in Arid Environment of China. International Journal of Remote Sensing, 29, 1093-1107. https://doi.org/10.1080/01431160701355256 